\title{
A IMPORTÂNCIA DA ESCOLA DE FRANKFURT PARA UMA NOVA LEITURA DE MARX ${ }^{1}$
}

\section{THE IMPORTANCE OF THE FRANKFURT SCHOOL FOR A NEW READING OF MARX}

\author{
Mario Schäbel ${ }^{2}$ \\ Recebido em: 07/2019 \\ Aprovado em: 11/2019
}

\begin{abstract}
Resumo: Dentro do marco das discussões atuais sobre uma nova interpretação de Marx, o artigo se ocupa com a obra de Alfred Schmidt, Hans-Georg Backhaus e Helmut Reichelt. Estes autores desenvolveram a interpretação de Marx que foi apresentada pela primeira geração da Escola de Frankfurt. O objetivo central do artigo é refutar a tese de que esta interpretação, baseada na Teoria Crítica, não leva em conta suficientemente a importância que teve a luta de classes para Marx. Além disso, se demonstrará que a crítica da economia política de Marx é o paradigma indubitável da Teoria Crítica e, portanto, sustentamos que a mudança de paradigma, proposta por Habermas, representou um afastamento de suas raízes.
\end{abstract}

Palavras-chave: Escola de Frankfurt; Nova Leitura de Marx; fetichismo; Alfred Schmidt; luta de classes.

\begin{abstract}
Within the framework of the actual discussions about a new interpretation of Marx, the article deals with the work of Alfred Schmidt, Hans-Georg Backhaus and Helmut Reichelt. These authors developed the interpretation of Marx which was presented by the first generation of the Frankfurt School. The article's main objective is to refute the thesis that claims that this interpretation based on Critical Theory doesn't take into account sufficiently the importance which class struggle had for Marx. Furthermore it shows, that Marx' critique of political economy is the undoubted paradigm for Critical Theory, and therefore, the paradigm change proposed by Habermas meant a distancing from its roots.
\end{abstract}

Keywords: Frankfurt School; New Reading of Marx; fetishism; Alfred Schmidt; class struggle.

\footnotetext{
${ }^{1}$ Publicado anteriormente em Mario Schäbel, La importancia de la Escuela de Frankfurt para una nueva lectura de Marx. Constelaciones - Revista de Teoría Crítica. Madrid, n. 8-9, p. 333-347, 2016-2017. Uma versão modificada foi posteriormente publicada em Mario Schäbel, Die Bedeutung der Frankfurter Schule für eine neue MarxLektüre. In: Dominik Novkovic, Alexander Akel (Hrsg.). Karl Marx - Philosophie, Pädagogik, Gesellschaftstheorie und Politik: Aktualität und Perspektiven der Marxschen Praxisphilosophie. Kassel: Kassel University Press, 2018. S. 97-116. Tradução do castelhano: Flademir Roberto Williges, professor de Filosofia do Instituto Federal do Rio Grande do Sul - Campus Porto Alegre. Doutor em Psicologia Social e Institucional pela Universidade Federal do Rio Grande do Sul. [N.T.].

2 Mestre em Estudos de Ciência Política, Filosofia e Ciência da Comunicação pela Ludwig-MaximiliansUniversität München (Alemanha) e doutorando em Sociologia pela Benemérita Universidad Autónoma de Puebla (México). Email: marioschaebel@gmail.com
} 
Em 2006 Ingo Elbe publicou Marx im Westen - Die neue Marx-Lektüre in der Bundesrepublik seit $1965^{3}$, livro que deu origem ao uso frequente do termo Neue Marx-Lektüre 4 para designar uma nova interpretação da obra de Marx radicada na crítica que os representantes do Marxismo Ocidental (Georg Lukács, Karl Korsch, a Escola de Frankfurt, etc) fizeram à interpretação dogmática de Marx por parte do Marxismo Ortodoxo. Neste artigo pomos o foco em uma variante desta nova interpretação, que Elbe nomeia Frankfurter Schule der neuen Marx-Lektüre ${ }^{5}$ e na qual inclui Hans-Georg Backhaus, Alfred Schmidt e Helmut Reichelt. Como indica o título, para estes autores a Escola de Frankfurt tem grande importância pela interpretação formulada sobre Marx.

Também levaremos em consideração que este enfoque tem seus críticos, inclusive dentro da própria Escola de Frankfurt, como é o caso de Jürgen Habermas, quem com sua proposta de mudança de paradigma em direção à teoria comunicativa quer deixar para trás as raízes marxistas da Teoria Crítica. Além disso, desde seu ponto de vista, Adorno se desinteressou das questões econômicas que ocuparam Marx e, portanto, suas considerações teóricas não são úteis para elaborar uma nova interpretação deste último (Habermas, 1975, p. $160)$.

Karl Reitter, professor de sociologia da Universidade de Viena, segue Habermas neste tipo de crítica. Publicou, em 2015, Karl Marx: Philosoph der Befreiung oder Theoretiker des Kapitals? - Zur Kritik der "Neuen Marx-Lektüre"”, livro que reúne artigos de diferentes autores que, em sua maioria, sustentam que a ênfase posta pelos representantes da Escola de Frankfurt e seus sucessores na totalidade como categoria central da crítica à sociedade capitalista provoca um descuido da importância que a luta de classes tem para Marx.

Não se trata, na realidade, de uma argumentação nova. Já foi dirigida, anteriormente, contra os membros da primeira geração da Escola de Frankfurt pelos representantes do movimento estudantil de 68, como é o caso de Hans-Jürgen $\mathrm{Krahl}^{7}$. Eles também os criticaram por ter uma interpretação pessimista da teoria de Marx, ao conceber o capitalismo como beco sem saída e, por conseguinte, não deixar nenhuma possibilidade para uma práxis revolucionária.

\footnotetext{
${ }^{3}$ Port.: Marx no Ocidente - A nova leitura de Marx na Alemanha desde 1965.

${ }^{4}$ Port.: Nova Leitura de Marx.

${ }^{5}$ Port.: A Escola de Frankfurt da Nova Leitura de Marx.

${ }^{6}$ Port.: Karl Marx: Filósofo da libertação ou teórico do capital? - Crítica da "Nova Leitura de Marx".

7 “Na pergunta abstrata e epistemológica do problema da constituição, torna-se decisivo o defeito prático da Teoria Crítica, porque teoricamente o antagonismo de classes, na verdade, não é parte da gênese desta teoria" (Krahl, 2008, p. 299).
} 
O objetivo central deste artigo é a refutação de tais argumentos e a defesa do enfoque de fundar uma nova interpretação de Marx sustentada na Escola de Frankfurt, tal como o fazem Backhaus, Schmidt e Reichelt. Por isso, refutaremos primeiro a acusação de Habermas dirigida a Adorno de que este não se ocupou da economia de Marx; posteriormente rebateremos a afirmação de Reitter de que a luta de classes não joga nenhum papel para a Escola de Frankfurt e seus sucessores.

Concentraremo-nos na Dialética negativa de Adorno porque compartilhamos a opinião de Backhaus de que esta obra, apesar de ser vista somente como filosófica, também contém muitas considerações econômico-teóricas (cf. Backhaus, [2012]).

Usaremos o conceito de fetichismo como fio condutor porque está no centro da interpretação de Marx apresentada pela Nova Leitura de Marx Frankfurtiana ${ }^{8}$, e desta maneira tornar visível o fundamento que tem esta corrente no Marxismo Ocidental, para o qual dito conceito também foi chave.

O artigo se dividirá em duas partes. Na primeira nos ocuparemos das questões que têm que ver com a crítica da economia política de Marx, interpretada como crítica de uma ciência. $\mathrm{Na}$ segunda, das questões relacionadas com a crítica da economia política interpretada como crítica de um sistema social.

\section{I.}

Do ponto de vista de Backhaus e Reichelt, existe uma analogia entre a crítica da economia política de Marx e a Dialética negativa de Adorno porque este critica os conceitos da teoria tradicional da mesma forma como o primeiro faz com as categorias da economia política. Assim como Adorno critica os conceitos tradicionais por se fundarem sobre uma abstração que aniquila a disparidade das coisas concretas subsumidas sob eles, Marx - com sua crítica às categorias econômicas - aponta uma abstração que não leva em conta as diferenças concretas dos bens trocados. Mas esta crítica da abstração que Backhaus e Reichelt colocam no núcleo de suas teses abarca mais aspectos que o recém descrito.

Reichelt destaca, neste contexto, que a abstração criticada por Adorno é uma abstração real e que esta deve ser conectada com o tema do fetichismo. Como é sabido, Marx critica em

\footnotetext{
8 “Se a economia na discussão centenária do Capital quase não colocou ênfase no subtítulo - crítica da economia política, no sentido de uma 'crítica às categorias econômicas' - a razão notória para isso é que a grande maioria dos economistas têm evitado e evita, como a peste, o tema central desta crítica, quer dizer, o caráter fetichista das categorias econômicas" (Backhaus, 1997, p. 34).
} 
Smith e Ricardo que, ao não se perguntarem "porque esse conteúdo adota essa forma" (Marx, 2010, p. 98), fetichizam o capitalismo no sentido de que o compreendem como a forma social natural, no lugar de uma forma histórica-específica. Em vez disso, Marx vê o fundamento de cada forma social na práxis humana e com isto insiste no caráter transitório do capitalismo e suas categorias. Exemplo disso seria a categoria do valor, que para os representantes da economia política significa uma propriedade intrínseca e natural dos bens, enquanto que para Marx é em realidade um produto social que nasce dos acordos aos quais chegam os sujeitos que trocam seus bens. E é aí onde entra em jogo a definição que Adorno tem de abstração real. Para ele, significa um "processo de constituição, ao qual pertence essencialmente o fato de que a gênese desvaneceu-se no resultado" (Reichelt, 2008, p. 24). Com relação ao exemplo do valor entendido como uma abstração real, pode-se dizer que, na definição que os economistas dão desta categoria, sua origem desvaneceu-se justamente porque fazem abstração do ato real da práxis social que estabelece o valor dos bens. Deve-se acrescentar, também, que quando Adorno fala da abstração real, parte de sua definição também é a de um processo de inversão mediante o qual os sujeitos que constituem as formas das relações sociais, como é o valor, convertem-se em meros executores destas formas. Nisto se aproxima do conceito de fetichismo de Marx, porque também se trata de um processo no qual os sujeitos constituintes se tornam objetos que são dominados por seu próprio produto.

Adorno coloca que cada teoria tradicional esquece que os conceitos têm uma origem histórica e os utiliza como absolutos à semelhança da economia política que vê o capitalismo como a forma natural de toda sociedade, apesar de tratar-se somente de uma forma social histórica específica. Um exemplo disso é a crítica de Adorno ao idealismo de Hegel, ao qual atribui um positivismo que procede de maneira semelhante ao da economia política, porque não leva em conta a práxis social que constitui as formas das relações sociais e dos conceitos. Portanto, Hegel cai em um "fetichismo dos conceitos" (Adorno, 2005, p. 187).

Adorno também destaca que os conceitos não são algo dado por natureza - como o é, no caso, a subjetividade absoluta do espírito, sobre a qual se funda o idealismo de Hegel -, senão que se originam no - e estão envolvidos - processo da totalidade social. "Então, a referência dialética à totalidade, para a Teoria Crítica, cumpre a função essencial da destruição da pseudoconcreticidade da aparência fetichista da imediatez, ou bem, da naturalidade de algo que na realidade é constituído e mediado socialmente" (Elbe, [2006]). Então, no lugar de conceber a subjetividade como uma força constitutiva independente do social - tal como o faz Hegel -, Adorno destaca que não somente o objeto é um produto do sujeito, mas que também 
o sujeito é um produto do objeto. Em outras palavras, a subjetividade, como princípio constitutivo, também é algo constituído pela sociedade.

Esta crítica de Adorno aos conceitos da teoria tradicional é o pano de fundo da tese de uma analogia entre seu trabalho e o de Marx sustentada pela Nova Leitura de Marx Frankfurtiana. Como mostramos, assim como Marx põe novamente em evidência a constituição das formas das relações sociais a partir da práxis humana, da mesma maneira Adorno se esforça em mostrar a origem social dos conceitos que a teoria tradicional pressupõe como algo absoluto; e por conseguinte, compreende a crítica que Marx faz à economia política como uma anamnese da gênese, formulado assim em uma troca de cartas com Alfred Sohn-Rethel (cf. Reichelt, 2008, p. 24). A Nova Leitura de Marx Frankfurtiana segue Adorno em sua compreensão de tal crítica, tal como o vemos em Backhaus que disse que a "característica distintiva mais importante" (Backhaus, 1997, p. 409) entre Marx e a economia política é que o autor de $O$ capital não somente pressupõe as formas das relações sociais como algo dado, mas também tenta deriválas geneticamente. Então sua crítica não consiste mais que na constatação de "que as relações sociais dos seres humanos se tornaram independentes. [...] Do que trata a crítica da economia política, [...] não somente o é da pura descrição deste fato mas da análise de sua gênese" (Ibid., p. 47).

Devido a que Marx localiza o fundamento das relações sociais na práxis social e dela deriva sua gênese, os representantes da Nova Leitura de Marx Frankfurtiana consideram que se trata de uma crítica ad hominem. Também nisso remetem-se à interpretação de Adorno, que determina o ponto principal da crítica de Marx como a intenção de "derivar relações independizadas desde o comportamento dos seres humanos" (Reichelt, 2008, p. 24).

Portanto, a nova interpretação de Marx que apresentam Reichelt, Schmidt e Backhaus, com relação a Adorno, se distingue fundamentalmente daquela do marxismo tradicional, e em particular da visão tradicional do materialismo histórico. A razão é que, diferentemente da interpretação marxista tradicional, estes pensadores não derivam o comportamento dos seres humanos das circunstâncias, mas ao contrário: as circunstâncias desde o comportamento. Desta maneira põem em dúvida o dogma tradicional de que o materialismo histórico de Marx toma as relações de produção supostamente como seu ponto de partida. Backhaus, por exemplo, remete-se ao conceito de sociedade de Adorno para substituir a primazia do econômico no marxismo tradicional pela primazia das relações sociais em geral: 
No primeiro plano da obra de Adorno está a sociedade como a unidade de sujeito e objeto em lugar dos "termos estabelecidos de superestrutura e base ou infraestrutura", os que necessariamente trivializam a dedução de ideologias, quer dizer, sua "derivação de leis estruturais como o caráter fetichista das mercadorias", o próton pseudos [...]. Então levanta a afirmação de que "a sociedade como sujeito e objeto são o mesmo, e ao mesmo tempo não são o mesmo" (Backhaus, 2007, p. 80).

Por sua vez, Alfred Schmidt compartilha a opinião de Backhaus de que o materialismo histórico não deve ser interpretado como um determinismo econômico. Em seu livro O conceito de natureza em Marx sustenta que este tem um caráter não ontológico. Com isso quer dizer que a primazia das relações de produção não deve ser entendida de maneira dogmática, mas crítica. De acordo com Schmidt, Marx reconhece a validez dessa primazia pela forma social histórica específica do capitalismo, porém não a afirma como algo positivo e, neste sentido, não a absolutiza. Isso mesmo vale para outras constatações de Marx; por exemplo, o trabalho abstrato como substância do valor ou a lei do valor como princípio regulativo do capitalismo. Em ambas não se trata de dogmas absolutos, mas de fatos que somente têm uma validez restringida à existência do capitalismo. Por conseguinte, para Alfred Schmidt o materialismo histórico de Marx é "uma teoria em retratação. Não é uma visão dogmática do mundo, mas um diagnóstico de um estado falso que deve ser abolido" (Schmidt, 1976a, p. 104). Segundo ele ante "os numerosos equívocos, frequentemente intencionados, nunca se insistirá bastante no fato de que o materialismo de Marx tende à sua própria superação" (Schmidt, 1976b, p. 156).

Em relação à interpretação do materialismo histórico que apresenta Schmidt, Ingo Elbe fala de uma "historização do materialismo histórico" (Elbe, 2010, p. 70) e a concebe como uma "reformulação de motivos centrais da Teoria Crítica clássica" (Id.). Desde nosso ponto de vista Elbe tem razão quando leva em conta que Adorno, na Dialética negativa, sustenta que o "ponto de fuga do materialismo histórico seria sua própria superação, a liberação do espírito com respeito à primazia das necessidades materiais no estado de sua satisfação" (Adorno, 2005, p. 195). Neste contexto podemos nos remeter também ao texto Sobre Lukács no qual Adorno escreve: "Mas a doutrina marxiana da prioridade do ser sobre a consciência não quer que se a entenda ontologicamente, mas como expressão de algo negativo, a saber: do predomínio da coisificação, das relações de produção nas quais os homens "involuntariamente entram"” (Adorno, 2010, p. 252). Adorno já havia criticado que para o marxismo ortodoxo a lei do valor representa uma lei natural social, enquanto Marx em realidade a descreve como um produto da história natural. Com isso, segundo Adorno, no marco de sua crítica da economia política, 
Marx quer apontar à inversão fetichista entre o social e o natural que converte a lei do valor, um produto social, em algo que supostamente está dado por natureza.

Deve acrescentar-se que, na Dialética negativa, Adorno (2005, p. 317) recorre a esta crítica do fetichismo feita por Marx e a aplica aos conceitos da teoria tradicional, quando usa para isso explicitamente o termo fetichismo (só que usa o de feitiço [hechizo] como equivalente ao de fetichismo). Neste contexto, com relação à lei do valor e sua fetichização no marxismo ortodoxo, escreve no mesmo livro:

Somente uma perversão dos motivos marxistas como a do Diamat, que prolonga o reino da necessidade enquanto assevera que seria o da liberdade, poderia sucumbir à falsificação do polêmico conceito marxista de legalidade natural convertendo-o de uma construção da história natural em uma doutrina científica de invariantes. Com isso, porém, o discurso marxista da história natural não perde nada de seu conteúdo de verdade, precisamente o conteúdo crítico (Ibid., p. 326).

O que nesta citação Adorno chama o conteúdo crítico de verdade do conceito da história natural expressa de forma condensada o que é a posição da Nova Leitura de Marx Frankfurtiana em relação ao materialismo histórico de Marx e sua teoria em geral. Seus representantes, em relação a Adorno, não simplesmente descartam os fatos, como o são o da primazia das relações de produção, do trabalho abstrato como substância do valor ou da lei do valor como princípio regulativo do capitalismo. O que negam é que estes fatos tenham uma validez além de algo que parece ser natural, enquanto que na realidade são algo historicamente produzido e, portanto, mutável. Definitivamente, pode-se dizer que a Nova Leitura de Marx Frankfurtiana interpreta a teoria de Marx como uma teoria crítica, em comparação com o marxismo tradicional que a interpreta como um dogma.

\section{II.}

Em 2008 Karl Reitter publicou Der bewegte Marx $^{9}$ onde critica a interpretação de Marx que o autor denomina marxismo de circulação [Zirkulationsmarxismus]. Neste livro expõe que a Nova Leitura de Marx pode ser considerada este tipo de interpretação e localiza sua origem na Escola de Frankfurt. O termo marxismo de circulação é explicado como uma interpretação da crítica da economia política que tem em seu centro uma concepção do valor ou do capital

\footnotetext{
${ }^{9}$ Port.: Marx em movimento.
} 
como sujeito automático e, portanto, concebe a forma da dominação no capitalismo como uma estrutura abstrata independizada dos sujeitos que no fundo a constituem.

Desta maneira, os sujeitos constituintes se convertem somente em auxiliares executivos do valor, o que também valeria para a classe burguesa. Quer dizer, inclusive os capitalistas não seriam nada mais que uma personificação da lei do valor ou, para agudizá-lo, somente seus escravos. Assim o "capitalismo se mostra como uma máquina anômima que não tem quem a controle e a dirija com sua vontade, alguém que se possa fazer responsável pelas destruições que foram causadas por esta" (Brugger, 2015, p. 185). Portanto, no marxismo de circulação a dominação de classe desaparece. Seus representantes, de acordo com Reitter, não chegam a compreender que no capitalismo a dominação social somente se apresenta "disfarçada de relações sociais de coisas" (Reitter, 2015, p. 14), porém, na realidade, trata-se de uma dominação de classe não de coisas.

Tobias Brugger ${ }^{10}$ fala, neste contexto, de uma duplicação da aparência. Desde seu ponto de vista, compreender o capital como sujeito automático significa cair na armadilha da aparência que é produzida pela superfície fetichicizada do capitalismo. Com isso faz alusão ao fato de que Marx, ao ter a concepção de capital desta maneira, unicamente faz referência à forma de capital como aparece na esfera da circulação, e por isso compreendê-la como sua verdade significaria uma fetichização do fetichismo, trazendo como consequência a mencionada duplicação. Então, desta maneira a Nova Leitura de Marx

paradoxalmente duplica a perspectiva que pretende criticar [...]. Em lugar de decifrar atrás do fetichismo das mercadorias, supostamente independizadas totalmente, a relação de classes, esta é concebida somente como algo quase externo à produção de mercadorias. [...]. Mas o capitalismo e, com isso, "o capital unicamente é resultado da luta de classes" (Hanloser/Reitter). O capital é uma "relação social entre pessoas mediada por coisas" (Marx) (Brugger, 2015, p. 191).

Por outra parte, Georg Klauda, outro autor incluído no livro de Reitter, qualifica ao marxismo de circulação como um "marxismo sem classes" (Klauda, 2015, p. 86), concedendolhe a Adorno ser seu "pai fundador" (Id.). A razão apoia-se em que o pensador frankfurtiano põe o enfoque de sua crítica nos temas da cultura e da civilização, omitindo a importância da luta de classes para Marx. Segundo Klauda, o pensamento de Adorno gira mais em torno a uma crítica da história nefasta da racionalidade ocidental do que a uma crítica da sociedade classista,

\footnotetext{
${ }^{10}$ Outro dos autores incluídos no livro já mencionado de Reitter.
} 
deslocando o feroz do capitalismo desde a esfera da produção - de onde sucede a separação violenta entre os seres humanos e seus meios de produção - à esfera da circulação, na qual as mercadorias são trocadas por meio da abstração do valor, perdendo assim sua particularidade. Além disso, a fixação do pensamento de Adorno no conceito de totalidade supostamente provoca que sua crítica degenere em uma teoria de sistemas "funcionalista". Klauda fundamenta esta reprovação na seguinte citação de Adorno: "A totalidade se consegue somente em virtude da unidade das funções desempenhadas por seus membros. Em geral, cada indivíduo tem que realizar, para ganhar a vida, uma função e se lhe ensina a ser agradecido enquanto a tem" (Adorno, 2004, p. 317).

Porém, o que Klauda não menciona é que na frase anterior a por ele citada, Adorno caracteriza sua própria declaração sobre a totalidade como "uma aproximação ainda excessivamente abstrata" (Id.). Por isso, ao nosso olhar, resulta uma simplificação ilícita sustentar que Adorno, em sua crítica ao capitalismo, unicamente põe o foco no conceito de totalidade, com o que não proporia algo diferente de que todos são dependentes de todos. Embora não exista nenhuma dúvida de que sua crítica se dirige contra a degradação dos seres humanos a uma mera função necessária para a conservação do sistema, nos atrevemos a asseverar que Adorno de nenhuma maneira pensa que a dominação da totalidade social sobre os sujeitos que a constituem é um fato absoluto. Em seu lugar, pode-se dizer que, ao referir-se à dominação da totalidade, esta é mencionada quase sempre junto ao fato de que nenhuma forma de relação social na realidade pode se independizar completamente da práxis social que a constitui. Assim, por exemplo, escreve em A lógica das ciências sociais: "A totalidade social não mantém nenhuma vida própria acima dos componentes que soma e os quais, na realidade, registra. Produz-se e reproduz-se em virtude de seus momentos particulares" (Adorno, 2008, p. 45). Pelo anterior queremos fazer menção, de maneira breve, a que Max Horkheimer compartilha esta opinião:

A ação conjunta dos homens na sociedade é a forma de existência de sua razão; nela empregam suas forças e afirmam sua essência. Mas, ao mesmo tempo, este processo e seus resultados são para eles algo estranho; aparecemlhes, com todo seu inútil sacrifício de força de trabalho e vidas humanas, com seus estados de guerra e sua absurda miséria, como uma força natural imutável, como um destino supra-humano (Horkheimer, 2003, p. 237).

Portanto, parece-nos equivocado imputar a Adorno uma concepção da independização da totalidade social como um fato irrevogável que se expressa, por exemplo, na forma de 
conceber o capital como sujeito automático. Melhor, já Adorno (e também Horkheimer) viu o que Reitter, Klauda e outros autores pensaram que não havia considerado: que tal independização representa uma ilusão real, o que quer dizer que no capitalismo realmente parece que o capital se automatizou e que conta com um poder que supera ao dos sujeitos dos quais na realidade depende. Nisto insistem tanto Backhaus como Reichelt quando realçam como já o mencionamos - que Adorno deriva a suposta independização da totalidade social a partir do comportamento dos seres humanos. Por isso tampouco surpreende que Adorno, na Dialética negativa, sinalize a possibilidade da depreciação da lei do valor como o motivo mais poderoso da teoria de Marx (cf. Adorno, 2005, p. 326); o que, desde nosso ponto de vista, junto ao já mencionado, silencia toda discussão sobre um pessimismo absoluto em seu pensamento.

Além disso, tanto Backhaus como Reichelt insistem explicitamente na importância que tem a luta de classes para Adorno. O primeiro explica, em seu ensaio Adorno und die metaökonomische Kritik der positivistischen Nationalökonomie ${ }^{11}$, que quando este fala de totalidade refere-se sempre a uma totalidade antagônica, e por antagônico quer dizer a relação de classes. Outro texto de Backhaus onde se sublinha a importância do antagonismo e da luta de classes para Adorno é Dialektik der Wertform ${ }^{12}$, sobretudo o epílogo (o qual trata do resumo dos apontamentos que fez em um seminário que Adorno deu em 1962). Backhaus inclusive chega a colocar que o conceito de totalidade antagônica - ao lado da abstração real - é o núcleo duro da teoria de Adorno. Por sua parte, Reichelt alude a que, de fato, Adorno teve claro que a situação inicial da troca de mercadorias baseia-se na injustiça pela qual, os que não possuem outra coisa além de sua força de trabalho, são forçados a vendê-la. Isto quer dizer que Adorno de nenhuma maneira omitiu o tema da exploração, como Reichelt descreve no que segue:

Em suas lições e seminários Adorno costumava qualificar a contradição principal da estrutura social burguesa na breve fórmula: no capitalismo há injustiça e injustiça [geht es mit rechten Dingen zu und doch nicht mit rechten Dingen]. Posteriormente fez-se uma precisão através da alusão ao círculo vicioso que implica a troca de equivalentes - sem troca de equivalentes não há exploração, porém tampouco há troca de equivalentes sem exploração; e em seguida, Adorno explicava o problema mediante o caráter específico do valor da mercadoria força de trabalho (Reichelt, 2008, p. 360).

Agora vamos desdobrar a análise do argumento de Reitter e dos autores de seu círculo segundo o qual a Nova Leitura de Marx Frankfurtiana e a Escola de Frankfurt em geral

\footnotetext{
${ }^{11}$ Port.: Adorno e a crítica metaeconômica da economia política positivista.

12 Port.: Dialética da forma do valor.
} 
consistem em uma "substituição da crítica social materialista por uma crítica cultural e civilizatória" (Klauda, 2015, p. 94). Com relação à primeira corrente, estamos de acordo com o que Ingo Elbe (2010, p. 68) destaca como a razão de sua gênese: “A Nova Leitura de Marx Frankfurtiana começa como autossuperação da orientação direcionada à crítica cultural da Teoria Crítica clássica”. Elbe aponta com isso ao fato de que Backhaus, Schmidt e Reichelt, em seu trabalho teórico, orientam-se mais em direção a questões econômicas que em direção a questões culturais; e, portanto, é mais que duvidoso o argumento de que tanto eles como seus precursores frankfurtianos negligenciam a crítica social materialista de Marx.

Pensamos que a refutação de Elbe é certeira, mas é preciso acrescentar que tampouco a primeira geração da Escola de Frankfurt, com sua crítica cultural e civilizatória, substitui a crítica social materialista de Marx. Melhor, a continua e a amplia através dela. Para respaldar esta tese podemos recorrer a Jürgen Habermas, que está convencido de que as categorias de Marx podem ser reencontradas na crítica cultural e civilizatória da escola citada: "frequentemente na forma de uma ortodoxia oculta, as categorias da teoria do valor-trabalho de Marx se revelam na aplicação da crítica cultural sem identificar-se como tais" (Habermas, 1978, p. 235). Exemplo disso é a categoria de mercadoria de Marx, que não somente tem um sentido econômico mas também é vista como uma forma determinada de relações sociais, como consta em uma nota de rodapé de $O$ capital:

Em certo modo, com o homem sucede o mesmo que com a mercadoria. Como não vem ao mundo com um espelho na mão, nem tampouco afirmando, como o filósofo fichteano, "eu sou eu", o homem se vê refletido primeiro somente em outro homem. Tão somente através da relação com o homem Paulo como semelhante, o homem Pedro se relaciona consigo mesmo como homem. Porém com isso também o homem Paulo, dos pés a cabeça, em sua corporeidade paulina, conta para Pedro como a forma em que se manifesta o genus [gênero] homem (Marx, 2010, p. 65).

O fato de que Adorno, em seu próprio exemplar de $O$ capital, tenha sublinhado esta citação sete vezes (cf. Braunstein, 2011, p. 302) é uma prova contundente da importância que para ele tem a categoria mercadoria de Marx. Todavia, para aprofundar esta importância é necessário referir-nos à teoria do antissemitismo da Escola de Frankfurt, a qual, de acordo com Stefan Gandler, não só mostra uma explicação para o holocausto mas “ao mesmo tempo é uma teoria geral da dominação, da repressão, sobretudo, porém não exclusivamente nas sociedades do capitalismo tardio" (Gandler, 2009, p. 29). O conceito chave para a teoria do antissemitismo é o de identificação projetiva que provém da psicanálise, que em princípio descreve um 
mecanismo de defesa. Mediante este, os sujeitos que não podem aceitar sua autoimagem negativa projetam certas propriedades suas que tentam deslocar para outra pessoa e a identificam segundo aquelas. Assim também o conceito antissemita de judeu representa uma acumulação de traços de caráter que, em geral, os seres humanos só raramente aceitam em si mesmos, como, por exemplo, mesquinho, insidioso, falso, furtivo etc. Aqui podemos recorrer outra vez a Gandler, que descreve o significado que possui a identificação projetiva para a primeira geração da Escola de Frankfurt:

Nossa tese, que retomamos de Horkheimer e Adorno, é a de que o chamado ódio ao outro é mais bem um ódio ao demasiado conhecido em si mesmo. Como na sociedade atual praticamente não há mais lugar para a autocrítica e a autorreflexão, o ódio às partes de um mesmo que ele não pode aceitar, por exemplo, por causa de certas regras sociais, se projeta em um ódio ao suposto outro, que em verdade é o mais próximo. Não se odeia o desconhecido no outro, mas o demasiado conhecido; o que alguém deveria - segundo a lógica vigente - odiar em si mesmo, odeia-se no outro" (Ibid., p. 123).

Para mostrar que a crítica cultural e civilizatória da Escola de Frankfurt baseia-se na crítica social materialista de Marx, enfocamos a categoria de mercadoria tal e como é desenvolvida em $O$ capital. Pensamos que com ela Marx, no fundo, não descreve nada diferente de uma identificação projetiva, no sentido como a usam Adorno e Horkheimer. Porém, nossa tese poderia ser estendida ao levar em conta o que Marx escreve no capítulo sobre o trabalho alienado nos Manuscritos econômico-filosóficos:

Se o homem enfrenta-se consigo mesmo, enfrenta-se também com o outro. O que é válido para a relação do homem com seu trabalho, com o produto de seu trabalho e consigo mesmo, vale também para a relação do homem com o outro e com o trabalho, e o produto do trabalho de outro. [...] A alienação do homem e, em geral, toda relação do homem consigo mesmo, somente encontra realização e expressão verdadeira na relação na qual o homem está com o outro. Na relação de trabalho alienado, cada homem considera, pois, aos demais segundo a medida e relação na qual se encontra consigo mesmo enquanto trabalhador (Marx, 1968, p. 113).

Também o que vemos nesta citação de Marx é que sua crítica ao capitalismo não se dirige exclusivamente contra a divisão de classes e os fenômenos econômicos que trazem consigo, como o são o trabalho alienado ou a exploração, mas também aborda questões concernentes às relações intersubjetivas e à relação do sujeito consigo mesmo, quer dizer, não apenas encontramos uma dimensão econômica, mas também uma social. Por conseguinte, o 
fato de que a Escola de Frankfurt inclua estas questões em sua própria crítica da sociedade capitalista não significa nenhum afastamento de Marx, como Reitter e outros sustentam.

\section{Conclusão}

Um dos objetivos centrais deste artigo foi refutar a tese de Habermas de que Adorno nunca se ocupou com as questões econômicas na teoria de Marx. Para mostrar seu erro, recorremos à analogia entre a Dialética negativa e a crítica da economia política que destacam os autores da Nova Leitura de Marx Frankfurtiana, para respaldar a ideia de que Adorno se ocupou com economia, tanto implícita como explicitamente. A crítica da filosofia tradicional que desdobra nessa obra nos ajuda a entender que as categorias da crítica de Marx que à primeira vista parecem exclusivamente econômicas, como valor ou fetichismo, na realidade têm um fundo filosófico. Habermas se equivoca precisamente porque não pode ver esta analogia implícita entre a filosofia de Adorno e as considerações econômicas de Marx. Consideramos que levar em conta essa analogia é um assunto crucial para cada interpretação futura da obra de Marx que se pretenda sustentar na Escola de Frankfurt.

Outro objetivo de nosso artigo foi mostrar que a Escola de Frankfurt pode jogar sim um papel importante para uma nova interpretação de Marx, e que é um preconceito reduzi-la a uma crítica cultural pessimista que somente se refere a Marx de um modo apressado. Por isso esclarecemos que, na teoria de Adorno, a categoria de totalidade de nenhuma maneira aponta para um pessimismo absoluto que nega a possibilidade de êxito da luta de classes. Sua ênfase no fato de que as formas das relações sociais sempre são produto da práxis humana nos permite pensar que há em sua teoria um resto de esperança para a mudança social. Da mesma forma, nesta consideração (como em algumas outras) reside a importância do pensamento de Adorno sobre uma nova interpretação de Marx, sobretudo, em relação ao materialismo histórico.

Por fim, fez-se alusão ao fato de que a Nova Leitura de Marx Frankfurtiana rejeita cada interpretação dogmática do materialismo histórico, o que também é outra razão que coloca em dúvida a suposição de que a Escola de Frankfurt com seu diagnóstico de uma dominação total se refira a uma verdade absoluta. Reitter e os demais autores que defendem esta opinião, desde o nosso ponto de vista, não alcançam entender a complexa relação entre realidade e ilusão nas declarações de Adorno em relação ao tema do fetichismo e, portanto, o criticam com um argumento que com a passagem do tempo se tornou obsoleto. 


\section{Referências}

ADORNO, T. W. Dialéctica negativa. Trad. Alfredo Brotons Muñoz. Madrid: Akal, 2005. (Obra Completa, 6).

ADORNO, T. W. Escritos sociológicos I. Trad. Augustín González Ruiz. Madrid: Akal, 2004. (Obra Completa, 8).

ADORNO, T. W. Respecto a Lukács. Trad. Joaquim Chamorro Mielke. Madrid: Akal, 2010. (Obra Completa, 20/1).

ADORNO, T. W. Sobre la lógica de las ciencias sociales. In: POPPER, K. R.; ADORNO, T. W.; DAHRENDORF, R.; HABERMAS, J. La lógica de las ciencias sociales. Trad. Jacobo Muñoz. México D.F.: Colofón, 2008. p. 41-71.

BACKHAUS, H.-G. Adorno und die metaökonomishe Kritik der positivistischen Nationalökonomie, [2012]. Verfügbar unter: https://www.caira.net/verlag/leseproben/backhaus-marx.adorno_lp-kritikvwl/. Zugriff am 28.03.2017.

BACKHAUS, H.-G. Dialektik der Wertform: Untersuchungen zur Marxschen Ökonomiekritik. Freiburg: Ça Ira, 1997.

BACKHAUS, H.-G. Entre la filosofía y la ciencia: La economia social marxiana como teoria crítica. In: BONEFELD, W.; BONNET, A.; HOLLOWAY, J.; TISCHLER, S. (Eds.). Marxismo abierto: una visión europea y latinoamericana. Buenos Aires: Herramienta, 2007. Vol. II.

BRAUNSTEIN, D. Adornos Kritik der politischen Ökonomie. Bielefeld: Transcript, 2011.

BRUGGER, T. Die ideologische Lesart der Neuen Marx-Lektüre als Totengräberradikaler Kritik. In: REITTER, K. (Hrsg.). Karl Marx: Philosoph der Befreiung oder Theoretiker des Kapitals? Zur Kritik der "Neuen Marx-Lektüre”. Wien: Mandelbaum, 2015. S. 179-202.

ELBE, I. Kritische Theorie versus Kritik der politischen Ökonomie? Kontroversen in der Debatte und ökonomische Gegenständlichkeit, [2006]. Verfügbar unter: http://www.rote-ruhruni.com/cms/IMG/pdf/Kritische_Theorie_und_Kritik_der_politischen_Okonomie.pdf. Zugriff am 28.03.2017.

ELBE, I. Marx im Westen: Die neue Marx-Lektüre in der Bundesrepublik seit 1965. Berlin: Akademie, 2010.

GANDLER, S. Fragmentos de Frankfurt: ensayos sobre la Teoría Critica. México: Siglo Veintiuno, 2009.

HABERMAS, J. Perfiles filosóficos-políticos. Trad. Manuel Jiménez Redondo. Madrid: Taurus, 1975.

HABERMAS, J. Zwischen Philosophie und Wissenschaft: Marxismus als Kritik. Frankfurt a. M.: Suhrkamp, 1978. 
HORKHEIMER, M. Teoría critica. Trad. Edgardo Albizu e Carlos Luis. Buenos Aires; Madrid: Amorrortu, 2003.

KLAUDA, G. Von der Arbeiterbewegung zur Kritischen Theorie. Zur Urgeschichte des Marxismus ohne Klassen. In: REITTER, K. (Hrsg.). Karl Marx: Philosoph der Befreiung oder Theoretiker des Kapitals? Zur Kritik der "Neuen Marx-Lektüre". Wien: Mandelbaum, 2015. S. 86-118.

KRAHL, H.-J. Konstitution und Klassenkampf: Zur historischen Dialektik von Emanzipation und proletarischer Revolution. Frankfur a.M.: Verlag Neue Kritik, 2008.

MARX, K. El capital. Trad. Pedro Scaron. Madrid: Siglo Veintiuno, 2010.

MARX, K. Manuscritos de economía y filosofia. Trad. Francisco Rubio Llorente. Madrid: Alianza, 1968.

REICHELT, H. Neue Marx-Lektüre: Zur Kritik sozialwissenschaftlicher Logik. Hamburg: VSA, 2008.

REITTER, K. (Hrsg.). Karl Marx: Philosoph der Befreiung oder Theoretiker des Kapitals? Zur Kritik der "Neuen Marx-Lektüre". Wien: Mandelbaum, 2015.

SCHMIDT, A. Die Kritische Theorie als Geschichtsphilosophie. München: Hanser, 1976a.

SCHMIDT, A. El concepto de naturaleza en Marx. Trad. Julia M. T. Ferrari de Prieto e Eduardo Prieto. México: Siglo Veintiuno, 1976b. 